\title{
The effects of a low dose OTA exposure on weanling piglet gut microbiota
}

\author{
Iulian Alexandru Grosu*1, Ana Elena Cismileanu1, Daniela Eliza \\ Marin', Ionelia Taranu ${ }^{1}$ \\ *Corresponding author: grosu.iulian@ibna.ro
}

${ }^{1}$ Laboratory of Animal Biology, National Institute for Research and Development for Biology and Animal Nutrition, Calea Bucuresti no. 1, Balotesti, Ilfov 077015, Romania

\section{ABSTRACT}

Feed contamination is a major concern to the pig farming industry. There is a growing concern towards the harmful effects that mycotoxins and especially ochratoxin A have on the overall health and development of pigs.

However the deleterious effects on the gastro-intestinal microbiota has not been studied thoroughly, especially at a low dose exposure. The current study proposed to investigate the effect of a sub-chronic dose of OTA on some of the important bacterial populations colonizing the pig gut as well as assessing the impact on SCFA production. The changes induced in bacterial populations not only affect the immune system of the pig but also influence the development of the mycotoxicosis. This paper highlights the impact of $0.05 \mathrm{mg} / \mathrm{kg}$ feed of OTA on the large intestine microbiota and on the SCFA production associated with it.

Keywords: Ochratoxin A, SCFAs, piglet microbiota, bacterial populations, RTPCR

\section{INTRODUCTION}

Among the undesirable contaminants provided for in Directive 2002/32/ EC, mycotoxins represent one of the most important feedstuff class toxin, due to their high presence in crops and fodder (Andretta et al., 2011; Malagutti, Zannotti, Scampini, \& Sciaraffia, 2005; Walker \& Christian Larsen, 2005). Mycotoxins are secondary fungal metabolites, that pose a danger to both human and animal health through the contaminated food or feed intake (Moretti, Pascale, \& Logrieco, 2019). These metabolites are highly resistant to technological food processing treatments and can incur further expenses (Shanakhat et al., 2018). One of the most frequent mycotoxins occurring in feed is ochratoxin A (OTA), a secondary toxic metabolite produced by various fungal 
species of the genus Penicillium and Aspergillus. Cereals used in feedstuff represent a source of continuous exposure to OTA for pigs (Duarte, Lino, \& Pena, 2011; Wan, Chen, \& Rao, 2020).

Large scale surveys on cereal samples have shown a concentration of OTA contamination ranging from $0.20-0.29 \mu \mathrm{g} / \mathrm{kg}$ in cereal and byproducts (Organization, 2008). Although the European Commission recommended a maximum limit for OTA of $0.05 \mathrm{mg} / \mathrm{kg}$ for pig feed (EC 576/2006) (Majeed, Khaneghah, Kadmi, Khan, \& Shariati, 2018), studies have shown that subchronic exposure could also lead to OTA accumulation pig meat products (Faucet, Pfohl-Leszkowicz, Dai, Castegnaro, \& Manderville, 2004; D. E. Marin \& Taranu, 2015).

OTA has a marked nephrotoxic and immunotoxic effect (Assunção, Pinhão, Loureiro, Alvito, \& Silva, 2019). Subsequent to oral intake, OTA is promptly assimilated and reaches the systemic circulation, having a half-life in serum of 72-120 hours (Tao et al., 2018). At the level of the digestive tract most OTA binds to proteins like albumin and other molecules (Duarte et al., 2011; Gan et al., 2017) after it is assimilated at the level of the small intestine, the bioavailability of it varying around 65\% (Bernáldez, Rodríguez, Delgado, Sánchez-Montero, \& Córdoba, 2018). OTA is metabolized mainly in the kidneys, liver and intestines (Wu et al., 2011; S. Yang et al., 2015). Throughout the metabolic phase, OTA is accumulated in the proximal tubules of the kidney, thus the concentration of OTA from kidneys is an important sign showing general exposure of animals to this mycotoxin (Tao et al., 2018). OTA is excreted in both urine and feces (Gambacorta, Olsen, \& Solfrizzo, 2019; Pfohl-Leszkowicz \& Manderville, 2007). OTA can also alter the production parameters in pigs affecting pig rearing and production (Broom, 2017).

Microbiota plays an essential role in a number of nutritional, physiological, developmental and immune processes of pigs which influence their overall health and growth performance (Liew \& Mohd-Redzwan, 2018). After ochratoxins and other mycotoxins are ingested from food, they come in contact and affect the gastrointestinal (GI) tract (Crespo-Piazuelo et al., 2019; Grosu, Pistol, Taranu, \& Marin, 2019). In general mycotoxins have been shown to induce changes within the pig microbiota composition, these communities alterations (Zhao et al., 2019) can be seen up to species taxon (Robert et al., 2017; H. Yang et al., 2017). The mycotoxin effects on the gastrointestinal tract and its microbiota are negative and deleterious (Taranu et al., 2015), with whole commensal bacteria communities numbers being reduced along with an overall increase of pathogenic genera populations (Matsui, Ishimoto-Tsuchiya, Maekawa, \& Ban-Tokuda, 2018) and weakening of the host immune system (Guo et al., 2014; H. Yang et al., 2017). These complex interactions between the gastrointestinal microbiota, host, and mycotoxins also significantly influence how the mycotoxicosis will develop further (Hermann-Bank, Skovgaard, 
Stockmarr, Larsen, \& Mølbak, 2013; Śliżewska, Markowiak-Kopeć, Sip, Lipiński, \& Mazur-Kuśnirek, 2020).

Included in the multitude of metabolites produced by the gastrointestinal microbiota, short-chain fatty acids (SCFAs) are saturated aliphatic fatty acids with fewer than six carbon atoms (Zhang, Yu, Chen, Su, \& Zhu, 2018). They are derived from the large intestine fermentation of carbohydrates of plant origin that have evaded digestion and assimilation in the small intestine by gut microbiota, even though it is known that non-digested proteins or peptides could also be used by microorganisms for SCFA synthesis (J.-J. Wang et al., 2019). SCFAs play an essential part in host homeostasis preservation and illness recuperation (Huang et al., 2020; H. Yang et al., 2017; Zhang et al., 2018; Zhao et al., 2019).

The present study proposes to investigate the impact that sub-chronic OTA exposure might have on the porcine microbiota and on the secondary metabolites (short chain fatty acids) produced by microorganisms. For this purpose we have chosen a $0.05 \mathrm{mg} / \mathrm{kg}$ feed concentration of OTA (Organization, 2008), this value being in line with the value established by the European Commission for pig feedstuff (EC 576/2006).

\section{MATERIALS AND METHODS}

\section{Experimental design}

The piglets were managed in conformity with the Law 206/2004 and the Council Directive 98/58 / EC of the EU Council for the handling and protection of animals used for experimental purposes.

The experimental protocol was approved by the Ethics Committee of the National Research-Development Institute for Animal Nutrition and Biology, Balotești, Romania (Ethics Committee no. 52/2014, Date of approval: March 10, 2014).

Six weanling, healthy weanling piglets, TOPIGS- 40 hybrids, were allocated in two groups of 3 piglets based on dietary make-up, as follows: (1) Control group given a standard diet; (2) OTA group given a standard diet contaminated with $50 \mathrm{ppb}$ OTA / kg feed.

The piglets were individually marked by ear tags and housed in boxes ( 3 piglets per box per experimental group) and were fed experimental diets for 30 days. They had unhindered access to water and food for the whole duration of the study. Before the completion of the study, the piglets were weighed and sacrificed. The colonic digesta was frozen immediately and stored at $-80^{\circ} \mathrm{C}$ until further use.

OTA ( $>98 \%$ pure by high performance liquid chromatography [HPLC]) administered as a contaminant in the OTA diet was acquired from FERMENTEC (Jerusalem, Israel). Ten mg of mycotoxin were dissolved in DMSO (dymethil 
sulfoxide) and mixed into the standard diet for a final feed concentration of 50 $\mu \mathrm{g} / \mathrm{kg}$, which was confirmed by ELISA.

\section{Microbial DNA extraction}

The microbial genetic material was extracted using the QIAamp DNA stool minikit extraction kit (QIAGEN, Dusseldorf, Germany), following the manufacturer's protocol, with the addition of an additional step in which the extraction was performed at $95^{\circ} \mathrm{C}$ to improve the isolation efficiency of the bacterial genetic material.

\section{Gas-Chromatography method for SCFAs determination}

Short-chain fatty acids (valeric and isovaleric acids, propionic, acetic, butyric and isobutyric acids) were analyzed in aqueous extracts from the piglet colonic digesta samples by gas chromatography used in a previous study (Grosu et al., 2020). In short, the colonic isolates were diluted in 1: 2 (w: v) distilled water, centrifuged at $12,000 \mathrm{~g}$ for 25 minutes followed by the injection of $1 \mu \mathrm{L}$ volume sample in split mode on a gas chromatograph (Varian, 430-GC) fitted with an $30 \mathrm{~m}$ long Elite-FFAP capillary column, and an inside diameter of $320 \mu \mathrm{m}$ with the thickness of the film of $0.25 \mu \mathrm{m}$ (Perkin Elmer, USA). Hydrogen was used as the carrier gas at a flow rate of $1.5 \mathrm{ml} /$ minute. The injector was set at $250^{\circ} \mathrm{C}$, and the split rate was $1: 40$. The flame ionization detector (FID) was set to $200^{\circ} \mathrm{C}$ and the column furnace was set to $110^{\circ} \mathrm{C}$. The oven temperature was raised to $170^{\circ} \mathrm{C}$ at a rate of $12^{\circ} \mathrm{C} / \mathrm{min}$, where it was maintained for 9.5 minutes. The analysis time was 10 minutes. The sample concentration was calculated referring to a standard commercial mixture of volatile fatty acids (CRM46975, Supelco, USA). The results were expressed as $\mu \mathrm{mol} / \mathrm{g}$.

\section{PCR and quantitative PCR analysis}

The primers used in the study were synthesized commercially (Invitrogen), and the targets of the selected primers were checked and updated using Primer BLAST from the GenBank database.

Several steps were followed in order to obtain standard curves, which were used for the quantification of the target bacterial groups gene copy numbers.

The first step was performed using the Corbett PCR system and the specific GoTaq Green Master Mix enzyme kit used in the PCR reaction. Primers 27F: 5'AGAGTTTGATCCTGGCTCAG-3; and 1492R: 5 GGTTACCTTGTTACGACTT-3 (33) were used to amplify the universal $16 \mathrm{~S}$ region of all bacteria in order to obtain template DNA. The amplification program comprises the following steps: initial denaturation 5 minutes at $95^{\circ} \mathrm{C}$ followed by 30 cycles of denaturation at 2 minutes and $95^{\circ} \mathrm{C}$, annealing 30 seconds at $58^{\circ} \mathrm{C}$, extension for 5 minutes at $72^{\circ} \mathrm{C}$. The final extension took place for 10 minutes at $72^{\circ} \mathrm{C}$. The reaction 
products were further purified using the PureLink PCR Purification Kit Invitrogen to purify the DNA template. Serial dilutions (1012 to 105 molecules $/ \mu \mathrm{l}$ ) of the purified and quantified genomic bacterial DNA were used for the generation of standard curves.

The quantification of the target bacteria genera DNA was performed using the RotorGene $Q$ series systems, with the primers from Table 1 and the following amplification program: initial denaturation 2 minutes at $95^{\circ} \mathrm{C}$ followed by 30 cycles of denaturation at 2 minutes and $95^{\circ} \mathrm{C}$, annealing 1 munite at the specific temperature for each bacteria genera (Table 1), extension for 1 minute at $72^{\circ} \mathrm{C}$ and a final extension step of 10 minutes at $72^{\circ} \mathrm{C}$. Sample fluorescence was measured at the last step of each cycle. The gene copy numbers of the target bacteria genera from the colonic digesta samples were determined by relating the Cq values to standard curves. The final copy number for each targeted bacteria genus was calculated using the following equation:

$$
\frac{\text { No. bacterial copies }}{\text { digesta grams }}=\frac{Q M * C * D V}{S * W}
$$

in which QM represents the quantitative mean of the copy number, $C$ represents the DNA concentration of each sample, DV was the dilution volume of extracted DNA, S was the DNA amount (ng) which was used in the experiment and W stands for the weight of the colonic sample (g)(Metzler-Zebeli et al., 2013).

Table 1. Sequences of species-specific primers used in the RT-PCR reaction

\begin{tabular}{|l|l|}
\hline Genus & Primer sequence \\
\hline Lactobacillus & $\begin{array}{l}\text { Fw 5`- AGCAGTAGGGAATCTTCCA -3` } \\
\text { Rv 5`- CACCGCTACACATGGAG -3 }\end{array}$ \\
\hline Clostridium & $\begin{array}{l}\text { Fw 5` AAATGACGGTACCTGACTAA -3` } \\
\text { Rv 5` - CTTTGAGTTTCATTCTTGCGAA -3` }\end{array}$ \\
\hline Enterobacter & $\begin{array}{l}\text { Fw 5`- CATTGACGTTACCCGCAGAAGAAGC -3` } \\
\text { Rv 5` - CTCTACGAGACTCAAGCTTGC -3` }\end{array}$ \\
\hline Prevotella & $\begin{array}{l}\text { Fw 5` - GGTTCTGAGAGGAAGGTCCCC -3 } \\
\text { Rv 5` - TCCTGCACGCTACTTGGCTG -3` }\end{array}$ \\
\hline Bifidobacter & $\begin{array}{l}\text { Fw 5` TCGCGTCCGGTGTGAAAG -3` } \\
\text { Rv 5` - CCACATCCAGCATCCAC -3` }\end{array}$ \\
\hline
\end{tabular}

\section{Statistical analysis}

The statistical analysis for determining the significance between sample groups or correlations between SCFAs and bacteria genera were performed 
using the XLSTAT package (http://www.xlstat.com). Values of $p$ lesser than 0.005 were considered to be significant. Results were reported as means of \pm SEM values.

\section{RESULTS AND DISCUSSION}

Effects of OTA on the concentration of short-chain fatty acids in the colon digesta

Concentrations of short-chain fatty acids are important indicators in assessing the health of the digestive tract in pigs (Zhao et al., 2019). The effects of OTA on the concentration of short-chain fatty acids in piglets' colon digesta are shown in Table 2 . The concentration of acetic acid was predominant in the colon digesta compared to other fatty acids, as opposed to that of isovaleric and isobutyric acids found in the lowest concentrations. Although no significant differences were recorded, most fatty acid concentrations (except isobutyric) were decreased in the presence of OTA, the most severely affected concentration being that of butyric acid with an average decrease of $33 \%$.

Table 2. Content in short chain fatty acids from colonic digesta collected from piglets

\begin{tabular}{|l|c|c|c|c|c|c|}
\hline $\begin{array}{l}\text { Experimental } \\
\text { group } \backslash \text { SCFA } \\
(\mu \mathrm{M} / \mathrm{g} \text { colon } \\
\text { digesta) }\end{array}$ & $\begin{array}{c}\text { Acetic } \\
\text { Acid }\end{array}$ & $\begin{array}{c}\text { Propionic } \\
\text { Acid }\end{array}$ & $\begin{array}{c}\text { Isobutyric } \\
\text { Acid }\end{array}$ & $\begin{array}{c}\text { Butyric } \\
\text { Acid }\end{array}$ & $\begin{array}{c}\text { Isovaleric } \\
\text { Acid }\end{array}$ & $\begin{array}{c}\text { Valeric } \\
\text { Acid }\end{array}$ \\
\hline $\mathrm{M}$ & $35.37 \pm 2.1$ & $15.75 \pm 0.3$ & $0.25 \pm 0.02$ & $5.74 \pm 0.2$ & $0.23 \pm 0.01$ & $0.77 \pm 0.1$ \\
\hline OTA & $25.79 \pm 4.2$ & $13.03 \pm 2.4$ & $0.26 \pm 0.04$ & $3.8 \pm 0.6$ & $0.2 \pm 0.03$ & $0.6 \pm 0.16$ \\
\hline$P$ value & 0.12 & 0.23 & 0.47 & 0.07 & 0.3 & 0.13 \\
\hline
\end{tabular}

* results are presented as means \pm SEM

Identification and quantification of important bacterial genera present in the colon microbiota

The main purpose of this study was to evaluate the harmful effect that OTA has on the composition of some target bacterial populations in the pig colon. Although no significant differences were found between the experimental groups at the level of bacterial genus, a trend toward significance $(\mathrm{p}<0.07)$ was observed for the genus Clostridium and Enterobacter respectively.

The most abundant bacterial genus observed was Bifidobacterium, in antithesis, the genus Clostridium registering the lowest population value (Table 3 ). The values of the logarithmic concentration of the bacterial genera identified from the colonic digesta are presented in Table 3. 
Table 3. Abundance of bacterial genera found in colonic digesta

\begin{tabular}{|c|c|c|c|c|c|}
\hline $\begin{array}{l}\text { Experimental } \\
\text { group/Bacterial } \\
\text { genus }\end{array}$ & Lactobacillus & Clostridium & Prevotella & Enterobacter & Bifidobacterium \\
\hline $\begin{array}{l}\text { Control } \\
\text { (number of } \\
\text { copies/g } \\
\text { digesta) }\end{array}$ & $\begin{array}{l}2.19 \times 10^{10} \\
\pm 2.8 \times 10^{9}\end{array}$ & $\begin{array}{c}5.85 \times 10^{8} \\
\pm 2.11 \times 10^{8}\end{array}$ & $\begin{array}{c}1.14 \times 10^{12} \\
\pm 6.67 \times 10 \\
10\end{array}$ & $\begin{array}{l}1.57 \times 10^{10} \\
\pm 4.92 \times 10^{9}\end{array}$ & $\begin{array}{c}4.83 \times 10^{14} \\
\pm 1.15 \times 10^{14}\end{array}$ \\
\hline $\begin{array}{l}\text { OTA } \\
\text { (number of } \\
\text { copies/g } \\
\text { digesta) }\end{array}$ & $\begin{array}{l}1.59 \times 10^{10} \\
\pm 2.08 \times 10^{9}\end{array}$ & $\begin{array}{c}3.54 \times 10^{8} \pm \\
1.19 \times 10^{8}\end{array}$ & $\begin{array}{l}9.27 \times 10^{12} \\
\pm 1.7 \times 10^{11}\end{array}$ & $\begin{array}{l}5.01 \times 10^{10} \\
\pm 10^{10}\end{array}$ & $\begin{array}{c}5.11 \times 10^{14} \\
\pm 8.76 \times 10^{13}\end{array}$ \\
\hline$p$ value & 0.12 & 0.06 & 0.18 & 0.05 & 0.36 \\
\hline
\end{tabular}

* results are presented as means \pm SEM

As can be seen in Table 3, OTA had a relatively mixed effect on the bacterial population, negatively affecting the genus Lactobacillus with a population decrease of $43.18 \%$ (Table 3 ) and Clostridium whose population is reduced by $10.65 \%$ (Table 3). At the same time, OTA has a positive effect on the genera Prevotella, whose population increases by $43.77 \%$ (Table 3 ), the genus Enterobacter with an increase of over $100 \%$ and Bifidobacterium which has a population growth of $38.71 \%$ (Table 3 ).

Also, correlations were observed between certain types of bacteria and the values of fatty acid concentrations in the colonic digesta of piglets (Table 4). The genus Prevotella is strongly associated with a high synthesis of most types of short-chain fatty acids, which is also mentioned in the literature (Matsui et al., 2018).

Table 4. Correlation between bacterial populations found in colon digesta and shortchain fatty acid production in the colon

\begin{tabular}{|l|c|c|c|c|c|c|}
\hline $\begin{array}{l}\text { Bacterial } \\
\text { genus/SCFA }\end{array}$ & $\begin{array}{c}\text { Acetic } \\
\text { acid }\end{array}$ & $\begin{array}{c}\text { Propionic } \\
\text { Acid }\end{array}$ & $\begin{array}{c}\text { Isobutyric } \\
\text { Acid }\end{array}$ & $\begin{array}{c}\text { Butyric } \\
\text { Acid }\end{array}$ & $\begin{array}{c}\text { Isovaleri } \\
\text { c Acid }\end{array}$ & $\begin{array}{c}\text { Valeric } \\
\text { Acid }\end{array}$ \\
\hline Lactobacillus & 0.37 & 0.52 & -0.02 & 0.54 & 0.28 & 0.25 \\
\hline Clostridium & 0.14 & -0.22 & -0.07 & 0.19 & 0.13 & -0.01 \\
\hline Prevotella & 0.68 & 0.81 & 0.41 & 0.78 & 0.67 & 0.62 \\
\hline Enterobacter & -0.82 & -0.84 & -0.60 & -0.82 & -0.73 & -0.57 \\
\hline Bifidobacterium & -0.67 & -0.54 & -0.65 & -0.64 & -0.80 & -0.70 \\
\hline
\end{tabular}

OTA alters the structure of the community and the functional composition of the genetic material of the microbiota of the digestive tract, with negative indirect effects on the host (Crespo-Piazuelo et al., 2019; Tozlovanu, FaucetMarquis, Pfohl-Leszkowicz, \& Manderville, 2006). 
Other studies revealed the complexity of interactions between gut microbiota and mycotoxins (Burel et al., 2013; Liew \& Mohd-Redzwan, 2018; Taheur et al., 2017).

Exposure to aflatoxin B1 induced a decrease of Prevotella and Lactobacillus in the colon of intoxicated piglets, while increasing Camplyobacter, Lachnospira and some members of Erysipelotrichaceae, Bacteroidales or Tremblayales families (Grosu et al., 2019; Taheur et al., 2017). Intoxication with deoxynivalenol also reshaped the gut microbiota communities by abundance altering of multiple microbial taxa, dysbiosis of Proteobacteria, Cyanobacteria, Actinobacteria and Firmicutes being the primary effects (Cano-Sancho, González-Arias, Ramos, Sanchis, \& Fernandez-Cruz, 2015; J.-J. Wang et al., 2019).

Secondary bacterial enteric disease, as a result of OTA-induced immunosuppression (Burel et al., 2013; D. E. Marin \& Taranu, 2015; Pierron, Alassane-Kpembi, \& Oswald, 2016), can significantly influence the complex clinical and morphological picture of OTA toxicity (Cano-Sancho et al., 2015; Kőszegi \& Poór, 2016; Tao et al., 2018). It is known that a large number of the bacteria species identified in colonic samples perform an essential role in the carbohydrates metabolism, lipid and protein synthesis (Duarte et al., 2011; Kelly et al., 2017; Konstantinov et al., 2004). Changes in the composition of communities indicated that bacterial species reacted differently to OTA (Robert et al., 2017; H. Yang et al., 2017). From a taxonomic point of view, the Bacteroidaceae family was much more strongly affected than that of Lactobacillaceae due to the OTA effect, also anaerobic species are more sensitive than anaerobic-facultative ones (Liew \& Mohd-Redzwan, 2018; Robert et al., 2017; W. Wang et al., 2019).

At the genus level, Bacteroides, Bifidobacter, Dorea, Escherichia, Enterobacter, Oribacterium, Ruminococcus and Syntrophococcus were the most significantly affected genera by OTA compared to the genus Lactobacillus which has the strongest resistance to OTA (Altafini, Armorini, Zaghini, Sardi, \& Roncada, 2017; Brunse et al., 2019; Guo et al., 2014; Liew \& Mohd-Redzwan, 2018; D. Marin et al., 2016). Changes in the secondary metabolites (such as short-chain fatty acids) of the intestinal microbiota, due to changes in diet or the composition of the constituent microorganisms, can lead to the prevention of a number of metabolic diseases.

\section{CONCLUSION}

Some of the most susceptible species of farm animals towards feed contaminated with OTA are represented by pigs, with the porcine chronic nephropathy being strictly associated with the OTA presence, with widely known symptomatology reported in the veterinary clinical publications (Stoev 
et al., 2012; Tung et al., 2019). High doses of the toxin can also cause liver damage and necrosis of intestinal and lymphatic tissue (D. Marin et al., 2016; W. Wang et al., 2019).

In counteracting the harmful effects of mycotoxins, short-chain fatty acids produced as a result of the process of microbial fermentation of dietary fiber appear to be critical mediators (Zhao et al., 2019). Our observations tend to confirm the similar results of other studies indicating that Prevotella is one of the largest producers of SCFA (Huang et al., 2020; Zhang et al., 2018). The results obtained from the identification and quantification approach are similar to those of other studies in the literature confirming the genera Lactobacillus, Prevotella, Clostridium, Enterobacter and Bifidobacterium as markers of swine health (Liew \& Mohd-Redzwan, 2018; Mi, Peng, Wu, Wang, \& Liao, 2019; Pierron et al., 2016). Although apparently OTA negatively influences the composition of the pig microbiota and the synthesis of SCFA, this direction of research remains insufficiently studied.

\section{ACKNOWLEDGEMENTS}

This work was financed thought the projects ADER 9.2.1 financed by Ministry of Agriculture and Rural Development.

\section{REFERENCES}

Altafini, A., Armorini, S., Zaghini, A., Sardi, L., \& Roncada, P. (2017). Tissue distribution of ochratoxin A in pigs after administration of two-levels contaminated diets. World Mycotoxin Journal, 10(3), 263-272.

Andretta, I., Kipper, M., Lehnen, C., Hauschild, L., Vale, M., \& Lovatto, P. (2011). Meta-analytical study of productive and nutritional interactions of mycotoxins in broilers. Poultry Science, 90(9), 1934-1940.

Assunção, R., Pinhão, M., Loureiro, S., Alvito, P., \& Silva, M. J. (2019). A multiendpoint approach to the combined toxic effects of patulin and ochratoxin a in human intestinal cells. Toxicology letters, 313, 120-129.

Bernáldez, V., Rodríguez, A., Delgado, J., Sánchez-Montero, L., \& Córdoba, J. J. (2018). Gene expression analysis as a method to predict OTA accumulation in dry-cured meat products. Food Analytical Methods, 11(9), 2463-2471.

Broom, L. (2017). Necrotic enteritis; current knowledge and diet-related mitigation. World's Poultry Science Journal, 73(2), 281-292.

Brunse, A., Martin, L., Rasmussen, T. S., Christensen, L., Cilieborg, M. S., Wiese, M., ... Sangild, P. T. (2019). Effect of fecal microbiota transplantation route of administration on gut colonization and host response in preterm pigs. The ISME journal, 13(3), 720-733. 
Burel, C., Tanguy, M., Guerre, P., Boilletot, E., Cariolet, R., Queguiner, M., . . . Oswald, I. P. (2013). Effect of low dose of fumonisins on pig health: Immune status, intestinal microbiota and sensitivity to Salmonella. Toxins, 5(4), 841-864.

Cano-Sancho, G., González-Arias, C. A., Ramos, A., Sanchis, V., \& Fernandez-Cruz, M. (2015). Cytotoxicity of the mycotoxins deoxynivalenol and ochratoxin A on Caco-2 cell line in presence of resveratrol. Toxicology in Vitro, 29(7), 1639-1646.

Crespo-Piazuelo, D., Migura-Garcia, L., Estellé, J., Criado-Mesas, L., Revilla, M., Castelló, A., ... Ballester, M. (2019). Association between the pig genome and its gut microbiota composition. Scientific reports, 9(1), 1-11.

Duarte, S. C., Lino, C. M., \& Pena, A. (2011). Ochratoxin A in feed of foodproducing animals: An undesirable mycotoxin with health and performance effects. Veterinary microbiology, 154(1-2), 1-13.

Faucet, V., Pfohl-Leszkowicz, A., Dai, J., Castegnaro, M., \& Manderville, R. A. (2004). Evidence for covalent DNA adduction by ochratoxin A following chronic exposure to rat and subacute exposure to pig. Chemical research in toxicology, 17(9), 1289-1296.

Gambacorta, L., Olsen, M., \& Solfrizzo, M. (2019). Pig urinary concentration of mycotoxins and metabolites reflects regional differences, mycotoxin intake and feed contaminations. Toxins, 11(7), 378.

Gan, F., Hou, L., Zhou, Y., Liu, Y., Huang, D., Chen, X., \& Huang, K. (2017). Effects of ochratoxin A on ER stress, MAPK signaling pathway and autophagy of kidney and spleen in pigs. Environmental toxicology, 32(10), 22772286.

Grosu, I. A., Pistol, G. C., Marin, D. E., Cişmileanu, A., Palade, L. M., \& Ţăranu, I. (2020). Effects of dietary grape seed meal bioactive compounds on the colonic microbiota of weaned piglets with Dextran Sodium Sulfateinduced colitis used as an inflammatory model. Frontiers in veterinary science, 7.

Grosu, I. A., Pistol, G. C., Taranu, I., \& Marin, D. E. (2019). The impact of dietary grape seed meal on healthy and aflatoxin B1 afflicted microbiota of pigs after weaning. Toxins, 11(1), 25.

Guo, M., Huang, K., Chen, S., Qi, X., He, X., Cheng, W.-H., . . Xu, W. (2014). Combination of metagenomics and culture-based methods to study the interaction between ochratoxin a and gut microbiota. Toxicological Sciences, 141(1), 314-323.

Hermann-Bank, M. L., Skovgaard, K., Stockmarr, A., Larsen, N., \& Mølbak, L. (2013). The Gut Microbiotassay: a high-throughput qPCR approach combinable with next generation sequencing to study gut microbial diversity. BMC genomics, 14(1), 1-14. 
Huang, J., Zhang, W., Fan, R., Liu, Z., Huang, T., Li, J., . . Xiong, T. (2020). Composition and functional diversity of fecal bacterial community of wild boar, commercial pig and domestic native pig as revealed by $16 \mathrm{~S}$ rRNA gene sequencing. Archives of microbiology, 202(4), 843-857.

Kelly, J., Daly, K., Moran, A. W., Ryan, S., Bravo, D., \& Shirazi-Beechey, S. P. (2017). Composition and diversity of mucosa-associated microbiota along the entire length of the pig gastrointestinal tract; dietary influences. Environmental microbiology, 19(4), 1425-1438.

Konstantinov, S. R., Favier, C. F., Zhu, W. Y., Williams, B. A., Klüß, J., Souffrant, W.B., . . . Smidt, H. (2004). Microbial diversity studies of the porcine gastrointestinal ecosystem during weaning transition. Animal Research, 53(4), 317-324.

Kőszegi, T., \& Poór, M. (2016). Ochratoxin A: molecular interactions, mechanisms of toxicity and prevention at the molecular level. Toxins, $8(4), 111$.

Liew, W.-P.-P., \& Mohd-Redzwan, S. (2018). Mycotoxin: its impact on gut health and microbiota. Frontiers in cellular and infection microbiology, 8, 60.

Majeed, M., Khaneghah, A. M., Kadmi, Y., Khan, M. U., \& Shariati, M. A. (2018). Assessment of ochratoxin A in commercial corn and wheat products. Current Nutrition \& Food Science, 14(2), 116-120.

Malagutti, L., Zannotti, M., Scampini, A., \& Sciaraffia, F. (2005). Effects of ochratoxin A on heavy pig production. Animal Research, 54(3), 179-184.

Marin, D., Motiu, M., Pistol, G., Gras, M., Israel-Roming, F., Calin, L., ... Taranu, I. (2016). Diet contaminated with ochratoxin A at the highest level allowed by EU recommendation disturbs liver metabolism in weaned piglets. World Mycotoxin Journal, 9(4), 587-596.

Marin, D. E., \& Taranu, I. (2015). Ochratoxin A and its effects on immunity. Toxin Reviews, 34(1), 11-20.

Matsui, H., Ishimoto-Tsuchiya, T., Maekawa, S., \& Ban-Tokuda, T. (2018). Diversity and population density of methanogens in the large intestine of pigs fed diets of different energy levels. Animal Science Journal, 89(10), 1468-1474.

Metzler-Zebeli, B. U., Schmitz-Esser, S., Klevenhusen, F., PodstatzkyLichtenstein, L., Wagner, M., \& Zebeli, Q. (2013). Grain-rich diets differently alter ruminal and colonic abundance of microbial populations and lipopolysaccharide in goats. Anaerobe, 20, 65-73.

Mi, J., Peng, H., Wu, Y., Wang, Y., \& Liao, X. (2019). Diversity and community of methanogens in the large intestine of finishing pigs. BMC microbiology, 19(1), 1-9.

Moretti, A., Pascale, M., \& Logrieco, A. F. (2019). Mycotoxin risks under a climate change scenario in Europe. Trends in food science \& technology, 84, 3840 . 
Organization, W. H. (2008). Safety evaluation of certain food additives and contaminants (Vol. 68): World Health Organization.

Pfohl-Leszkowicz, A., \& Manderville, R. A. (2007). Ochratoxin A: An overview on toxicity and carcinogenicity in animals and humans. Molecular nutrition \& food research, 51(1), 61-99.

Pierron, A., Alassane-Kpembi, I., \& Oswald, I. P. (2016). Impact of mycotoxin on immune response and consequences for pig health. Animal Nutrition, 2(2), 63-68.

Robert, H., Payros, D., Pinton, P., Théodorou, V., Mercier-Bonin, M., \& Oswald, I. P. (2017). Impact of mycotoxins on the intestine: are mucus and microbiota new targets? Journal of Toxicology and Environmental Health, Part B, 20(5), 249-275.

Shanakhat, H., Sorrentino, A., Raiola, A., Romano, A., Masi, P., \& Cavella, S. (2018). Current methods for mycotoxins analysis and innovative strategies for their reduction in cereals: an overview. Journal of the Science of Food and Agriculture, 98(11), 4003-4013.

Śliżewska, K., Markowiak-Kopeć, P., Sip, A., Lipiński, K., \& Mazur-Kuśnirek, M. (2020). The effect of using new synbiotics on the turkey performance, the intestinal microbiota and the fecal enzymes activity in turkeys fed ochratoxin a contaminated feed. Toxins, 12(9), 578.

Stoev, S. D., Gundasheva, D., Zarkov, I., Mircheva, T., Zapryanova, D., Denev, S., . . . Mwanza, M. (2012). Experimental mycotoxic nephropathy in pigs provoked by a mouldy diet containing ochratoxin A and fumonisin B1. Experimental and Toxicologic Pathology, 64(7-8), 733-741.

Taheur, F. B., Fedhila, K., Chaieb, K., Kouidhi, B., Bakhrouf, A., \& Abrunhosa, L. (2017). Adsorption of aflatoxin B1, zearalenone and ochratoxin A by microorganisms isolated from Kefir grains. International journal of food microbiology, 251, 1-7.

Tao, Y., Xie, S., Xu, F., Liu, A., Wang, Y., Chen, D., ... Wang, X. (2018). Ochratoxin A: Toxicity, oxidative stress and metabolism. Food and Chemical Toxicology, 112, 320-331.

Taranu, I., Braicu, C., MARIN, D., Gras, M., Motiu, M., Pistol, G., . . BerindanNeagoe, I. (2015). Fusariotoxin Zearalenone affects genome-wide expression at local and systemic level in pig: 149/692. Annals of Nutrition and Metabolism, 67.

Tozlovanu, M., Faucet-Marquis, V., Pfohl-Leszkowicz, A., \& Manderville, R. A. (2006). Genotoxicity of the hydroquinone metabolite of ochratoxin A: structure-activity relationships for covalent DNA adduction. Chemical research in toxicology, 19(9), 1241-1247.

Tung, K.-K., Chan, C.-K., Zhao, Y., Chan, K.-K. J., Liu, G., Pavlovic, N. M., \& Chan, W. (2019). Occurrence and environmental stability of aristolochic acids in groundwater collected from Serbia: links to human exposure and 
Balkan endemic nephropathy. Environmental science \& technology, 54(3), 1554-1561.

Walker, R., \& Christian Larsen, J. (2005). Ochratoxin A: previous risk assessments and issues arising. Food additives and contaminants, 22(s1), 6-9.

Wan, J., Chen, B., \& Rao, J. (2020). Occurrence and preventive strategies to control mycotoxins in cereal-based food. Comprehensive Reviews in Food Science and Food Safety, 19(3), 928-953.

Wang, J.-J., Zhang, R.-Q., Zhai, Q.-Y., Liu, J.-C., Li, N., Liu, W.-X., ... Shen, W. (2019). Metagenomic analysis of gut microbiota alteration in a mouse model exposed to mycotoxin deoxynivalenol. Toxicology and applied pharmacology, 372, 47-56.

Wang, W., Zhai, S., Xia, Y., Wang, H., Ruan, D., Zhou, T., ... Ye, H. (2019). Ochratoxin A induces liver inflammation: involvement of intestinal microbiota. Microbiome, 7(1), 1-14.

Wu, Q., Dohnal, V., Huang, L., Kuca, K., Wang, X., Chen, G., \& Yuan, Z. (2011). Metabolic pathways of ochratoxin A. Current drug metabolism, 12(1), 110.

Yang, H., Huang, X., Fang, S., He, M., Zhao, Y., Wu, Z., . . Huang, L. (2017). Unraveling the fecal microbiota and metagenomic functional capacity associated with feed efficiency in pigs. Frontiers in microbiology, 8 , 1555.

Yang, S., Zhang, H., De Saeger, S., De Boevre, M., Sun, F., Zhang, S., ... Wang, Z. (2015). In vitro and in vivo metabolism of ochratoxin A: a comparative study using ultra-performance liquid chromatographyquadrupole/time-of-flight hybrid mass spectrometry. Analytical and bioanalytical chemistry, 407(13), 3579-3589.

Zhang, Y., Yu, K., Chen, H., Su, Y., \& Zhu, W. (2018). Caecal infusion of the shortchain fatty acid propionate affects the microbiota and expression of inflammatory cytokines in the colon in a fistula pig model. Microbial biotechnology, 11(5), 859-868.

Zhao, J., Bai, Y., Tao, S., Zhang, G., Wang, J., Liu, L., \& Zhang, S. (2019). Fiber-rich foods affected gut bacterial community and short-chain fatty acids production in pig model. Journal of Functional Foods, 57, 266-274. 